\title{
Ensino do Campo Magnético de um Ímã em Forma de Barra Utilizando Recursos de Realidade Aumentada
}

\author{
Teaching of the Magnetic Field of a Bar Shaped \\ Magnet Using Resources of Augmented Reality
}

\begin{abstract}
Resumo: Propõe-se neste trabalho apresentar um Objeto de Aprendizagem para o ensino do campo magnético de um ímã em forma de barra desenvolvido em ambiente de Realidade Aumentada. No ambiente criado em Realidade Aumentada há a presença simultânea de objetos reais e virtuais. Este Objeto de Aprendizagem pode servir de apoio à aula convencional no estudo dos campos magneticos dos imãs. Foram feitas análises e avaliações para a conclusão do trabalho, destacando-se as suas vantagens no processo de

Palavras-chave: Realidade Aumentada. Ímã em forma de barra. Magnetismo.

Abstract: It is proposed in this paper to present a Learning Object for teaching of magnetic fields of a bar shaped magnet developed in Augmented Reality environment. In the environment created in Augmented Reality there is the simultaneous presence of real and virtual objects. This Learning classroom to study the magnetic fields of magnets. Reviews its advantages in the learning process. Keywords: Augmented Reality. Bar shaped magnet. Magnetism.
\end{abstract}

\section{Suzana da Hora Macedo Instituto Federal Fluminense Universidade Federal do Rio Grande do Sul \\ Maria Cristina Villanova Biazus}

Universidade Federal do Rio Grande do Sul

Filipe Arantes Fernandes Centro Universitário São José de Itaperuna
MACEDO, Suzana da Hora; BIAZUS Maria Cristina Villanova; FERNAND,ES, Filipe Arantes. Ensino do Campo Magnético de um Imấ em Forma de Barra Utilizando Recursos de Realidade Aumentada. Informática na Educação: teoria \& prática, Porto Alegre, v. 14, n. 1, p.

\section{Introdução}

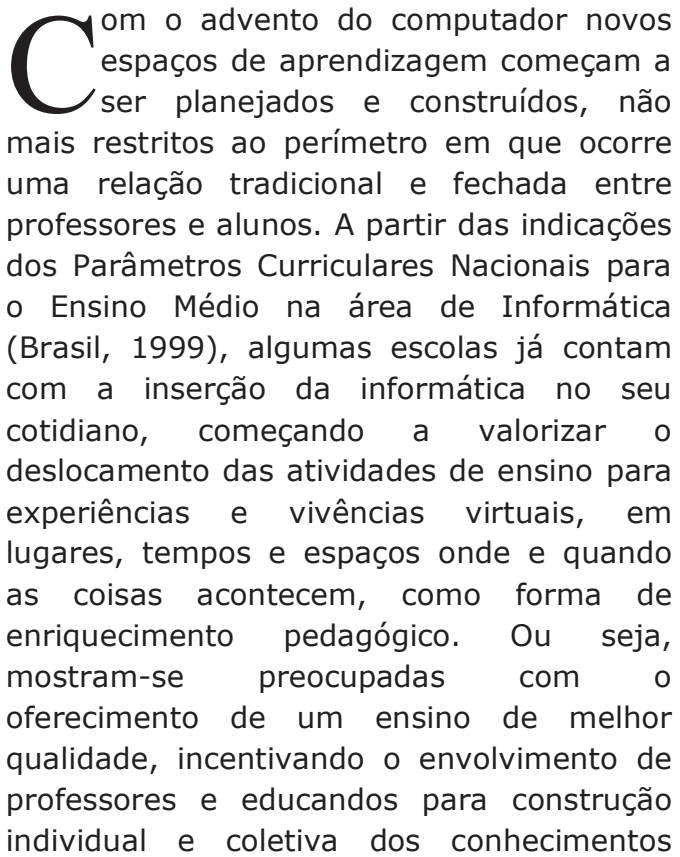


(Kenski, 2003). A informática permite a criação de novas formas de aprendizagem e de comunicação, instigando o aluno a conhecer o mundo de forma mais crítica.

Neste trabalho, foi elaborado um Objeto de aprendizagem desenvolvido em ambiente de Realidade Aumentada que proporcionará ao estudante interatividade e visualização em terceira dimensão do campo magnético de um ímã em forma de barra. Segundo GUILLERMO et al (2005, p.2), "as simulações tem se destacado como ótimos objetos de aprendizagem, principalmente na área das engenharias, ou até das ciências exatas". Este objeto servirá para ampliar o horizonte do aluno, possibilitando a interação deste aluno com o fenômeno físico em estudo, oportunizando também que ele visualize no mundo virtual objetos que seres humanos não conseguem visualizar no mundo real.

Nesse contexto, a informática pode vir a contribuir positivamente para acelerar o desenvolvimento cognitivo e intelectual do aluno, em especial no que esse desenvolvimento diz respeito ao raciocínio lógico e formal, à capacidade de pensar com rigor e sistematicidade, à habilidade de inventar ou encontrar soluções para problemas (Costa, 1998). Pode também possibilitar ao educando o desenvolvimento de sua capacidade de aprender a aprender, estimulando sua autonomia - que tem como fundamento o aprender fazendo experimentando e criando. Essa é hoje uma prioridade da escola que, utilizando-se dessa nova tecnologia, pode tornar esse processo mais rico e prazeroso (Coll, 2000).

Segundo Kenski, os ambientes digitais, pela não-linearidade que oferecem, ajudam a formar novas idéias e estimulam novas relações com o conhecimento. A interatividade provoca uma verdadeira revolução na sala de aula, rompendo com o paradigma estruturalista da emissãorecepção de mensagens. Os alunos são convidados a construir percursos, a serem autores da própria navegação (2003).

Sobre essa questão Moran (2000) coloca que o desenvolvimento da tecnologia da informação e o conhecimento estão provendo a possibilidade de transformar o processo de ensino-aprendizagem, contribuindo para quebrar as barreiras do ensino tradicional.

Visando trabalhar mais dinamicamente os conteúdos, a escola, atenta aos interesses dos jovens, pode então planejar atividades educacionais contando com o uso de softwares e bibliotecas, por meio dos quais o professor possa ensinar, simular, estimular a curiosidade ou, simplesmente produzir trabalhos com qualidade (Tajra, 2001).

Segundo LEMOS E CARVALHO, o software educativo "... pode ser a interface entre os professores e os estudantes como uma ferramenta auxiliar para melhorar os processos de ensino e de aprendizagem de um conteúdo ou assunto educacional ..." (2010, p. 2). Para que este processo aconteça, no nosso estudo, a Realidade Aumentada foi utilizada como apoio no ensino do campo magnético de um ímã em forma de barra.

O estudo dos campos magnéticos dos ímãs é importante desde o Ensino Médio, já que está inserido na disciplina de Física, assim com é importante nos cursos técnicos de Eletrotécnica e também nas Engenharias.

A compreensão dos fenômenos eletromagnéticos é base científica para o estudo das Máquinas Elétricas Girantes que são os fundamentos da conversão eletromecânica de energia. A matriz energética do Brasil está alicerçada sobre a energia elétrica. Essa energia elétrica, na quase sua totalidade, é obtida por meio de processo de conversão de energia mecânica associada aos ventos, às quedas d'água, turbinas movidas a gás, óleo, vapor, entre outros.

A conversão dessa energia mecânica em elétrica só é possível graças à interação de campos magnéticos rotativos cuja base científica é o Eletromagnetismo.

A indústria utiliza dos mesmos princípios para gerar movimento a partir da eletricidade, o que torna o assunto de suma importância na carreira de um eletrotécnico. Mesmo já fazendo parte do currículo do Ensino Médio, este assunto retorna ao estudo do aluno de Engenharia. Mais ainda: se este estudante for de Engenharia Elétrica, este assunto nuca irá abandoná-lo, tamanha a sua importância. 
$\begin{array}{ccl}\text { Verifica-se que as } & \text { dificuldades } & \text { de } \\ \text { aprendizagem dos } & \text { conteúdos } & \text { de } \\ \text { Eletromagnetismo se concentram } & \text { na }\end{array}$ impossibilidade de visualização dos campos magnéticos por parte dos alunos no espaço tridimensional. Segundo PAZ, "Constatamos que as dificuldades de aprendizagem dos conteúdos de Eletromagnetismo se concentram no entendimento das interações e comportamento das variáveis eletromagnéticas no espaço tridimensional, [...]" (2007, p.viii.).

\section{Realidade Aumentada como Facilitadora da Aprendizagem}

Segundo BARROS (2007), "A cada tema o usuário vai participar do ambiente virtual gerado pelo computador, .... Neste caso, o ambiente virtual será projetado para simular tanto um ambiente imaginário quanto um ambiente real". Com este objeto de Aprendizagem será simulado um ambiente que é impossível de ser visto a olho nu: o campo magnético. O campo magnético está presente em todos os lugares da Terra, porém em freqüências que não podem ser vistas pelos seres humanos. Existe o campo magnético da própria Terra, os campos magnéticos criados pelas antenas, onde recebemos diversos tipos de sinais, tais como via satélite, via cabo, ondas que trafegam pela ionosfera, entre outros. Tais campos magnéticos não podem ser observados a olho nu. Porém, a sua compreensão é de extrema importância no estudo das Máquinas Elétricas Girantes, assim como na área de Telecomunicações. Sendo assim, a Realidade Aumentada trará no mundo virtual este campo magnético, que será superposto ao ímã, que está no mundo real e pode assim ser visto pelo olho humano. Este Objeto de Aprendizagem permitirá o estudo dos campos magnéticos como nunca foi realizado anteriormente, onde o aluno terá a oportunidade de ver estes campos e também de interagir com os mesmos.

COSTA E PAIM (2004, p.28) afirmam que a simulação "permite que sistemas complexos sejam representados através de modelos no computador favorecendo de forma relevante o processo de aprendizagem". Nesse contexto, os campos magnéticos serão representados no mundo virtual e poderão ser visualizados pelos estudantes, com o objetivo de facilitar o seu estudo.

Milgran e Kishino (1994) afirmam que a Realidade Aumentada é a combinação de objetos reais e virtuais. No estudo do campo magnético de um ímã em forma de barra o objeto real utilizado foi o ímã e o objeto virtual é o seu campo magnético. Com o apoio da Realidade Aumentada o aluno pode ver em terceira dimensão o campo magnético de um ímã em forma de barra. Tal fenômeno não é possível de ser visto a olho nu, pois os campos magnéticos não são visíveis pelo olho humano. Para fins de ensino, utiliza-se pulverizar limalha de ferro ao redor de um ímã, conforme a figura 1 .

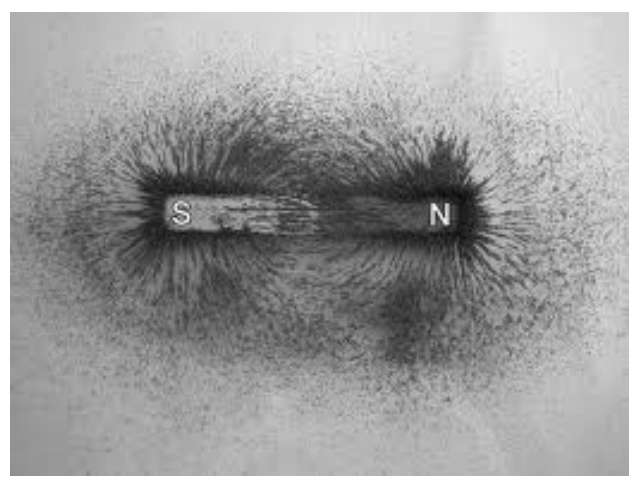

Figura 1 - Representação do campo magnético de um ímã com limalha de ferro

Fonte: http://fuches.wordpress.com/

Coloca-se um ímã em cima de uma superfície lisa e, delicadamente se pulveriza limalha de ferro bem fina, formando-se assim uma figura que seria uma representação do campo magnético. Porém, mesmo se utilizando de elementos reais, esta representação é bidimensional, trazendo grandes dificuldades aos alunos no sentido de que os mesmos têm que imaginar um campo magnético tridimensional a partir de uma figura bidimensional. Além disto, há uma grande dificuldade de se trabalhar com a limalha de ferro, que é muito leve e, com qualquer movimento, não permanece estática, atrapalhando toda a demonstração. 
Porém, como afirmam Buchau et al (2009), os problemas da vida real são em terceira dimensão. A Realidade Aumentada pode ajudar neste aspecto, pois com esta tecnologia é possível mostrar esses campos magnéticos em terceira dimensão, e campos magnéticos invisíveis podem ser mostrados em um ambiente de Realidade Aumentada.

Segundo Kaufmann et al, a principal vantagem do uso da Realidade aumentada é que os estudantes realmente vêem os objetos tridimensionais (2005, p. 1-2). Desse modo, neste trabalho, o campo magnético de um ímã em forma de barra foi demonstrado no mundo virtual, interagindo com o mundo real. Segundo Buchau et al (2009), a Realidade Aumentada ajuda os estudantes a entenderem a teoria do campo eletromagnético. Neste trabalho, a Realidade Aumentada possibilitará a visualização em três dimensões e interação com o campo magnético em estudo, fazendo com que o estudante visualize no mundo virtual objetos que não consegue visualizar no mundo real. Esse ambiente em Realidade Aumentada atuará como Objeto de Aprendizagem.

Com apoio da Realidade Aumentada o aluno pode ver em terceira dimensão o campo magnético de um ímã em forma de barra, fenômeno que é impossível de ser visto pelos seres humanos. De acordo com BARROS (2007, p.119), "professor, aluno, classe, estão todos envolvidos no tema de modo participativo, imersos no ambiente virtual construído para cada objetivo". Portanto, a Realidade Aumentada ampliará o horizonte do estudante, oportunizando uma situação de aprendizagem bastante diferente do ensino convencional.

De acordo com Souza e Kirner (2011), a vantagem de usar a Realidade Aumentada em vez de um experimento real é que o aluno tem a possibilidade de ver o cenário enriquecido com outras informações. No caso deste experimento o aluno terá o ímã (mundo real) com o cenário enriquecido pela visualização do seu campo magnético (mundo virtual) em um ambiente de Realidade Aumentada.

\section{Algumas Propostas de Uso de Realidade Aumentada na Educação}

Apesar de relativamente nova, essa tecnologia já vem sendo utilizada com sucesso em diversas áreas. Segundo VALENTE (1993), "a cada dia surgem novas maneiras de usar o computador como um recurso para enriquecer e favorecer o processo de aprendizagem". Diversos pesquisadores estão criando ambientes em Realidade Aumentada com o objetivo de facilitar a aprendizagem. Algumas propostas de uso da Realidade Aumentada na Educação serão abordadas a seguir.

Buchau et al (2009), criaram três aplicações baseadas em Realidade Aumentada para serem utilizadas no ensino do campo magnético de um ímã, do campo magnético de um solenóide e do campo magnético de uma antena. Na figura 2, pode-se ver o campo magnético de um solenóide, resultado deste trabalho.

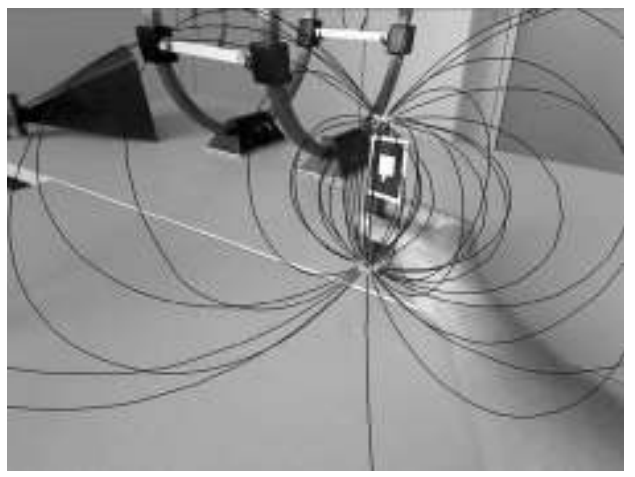

Figura 2 - Campo magnético criado por um solenóide Fonte: Buchau et al (2009)

Estas aplicações permitem que o aluno visualize os campos magnéticos em três dimensões. Este trabalho ainda não apresenta resultados de utilização das aplicações com estudantes.

Também utilizando a Realidade Aumentada no ensino, Lemos e Carvalho (2010) criaram o SISEULER, que atua como Objeto de Aprendizagem, onde o aluno pode ter um melhor entendimento da relação de Euler através da visualização e manipulação de objetos. O software SISEULER foi implementado com técnicas de Realidade 
Aumentada e utilizado para apoio ao ensino da Relação de Euler. O software baseado em Realidade Aumentada permite ao aluno a visualização em terceira dimensão e também a interação com os objetos. Neste trabalho, a Relação de Euler é utilizada para associar o número de vértices, faces e arestas dos poliedros. Este experimento foi testado com um resultado positivo com professores da educação básica que estão cursando mestrado profissional em Educação Matemática. A figura 3 mostra um dodecaedro utilizando o SISEULER.

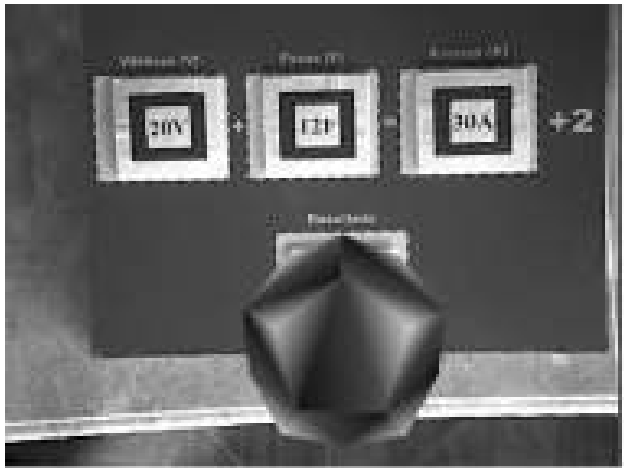

Figura 3 - Dodecaedro no SISEULER criado por Lemos e Carvalho

Fonte: Lemos e Carvalho (2010)

Macedo et al (2010) apresentaram um Método de Ensino de Sólidos utilizando Realidade Aumentada, proporcionando ao estudante a interação e visualização dos sólidos. A figura 4 mostra a usuária em um ambiente de Realidade Aumentada manipulando uma pirâmide.

Neste trabalho diversos sólidos podem ser vistos em terceira dimensão e também podem ser manipulados pelo estudante. A grande vantagem, além da visualização em terceira dimensão e da manipulação é que o custo é baixíssimo, já que, após feita a programação, o equipamento necessário se resume apenas a um laptop com web cam.

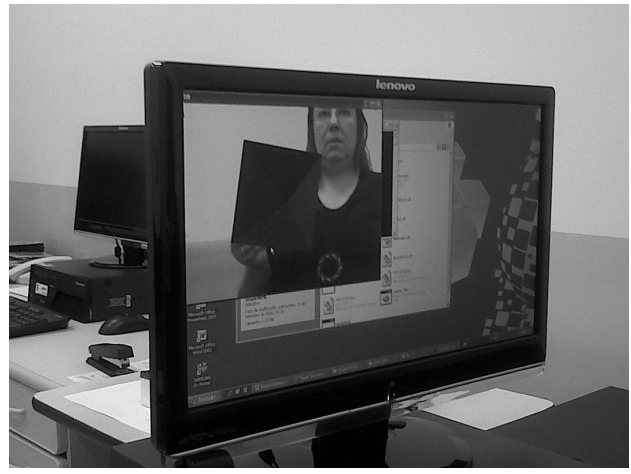

$$
\begin{gathered}
\text { Figura } 4 \text { - Usuária manipulando uma pirâmide em } \\
\text { Realidade Aumentada } \\
\text { Fonte: Macedo et al (2010) }
\end{gathered}
$$

Lima et al elaboraram o VSTARGD (Viewer of Torus Surfaces of Descriptive Geometry Through Reality). Neste software se pode visualizar superfícies tóricas, onde três são animadas. A figura 5 mostra a o VSTARGD.

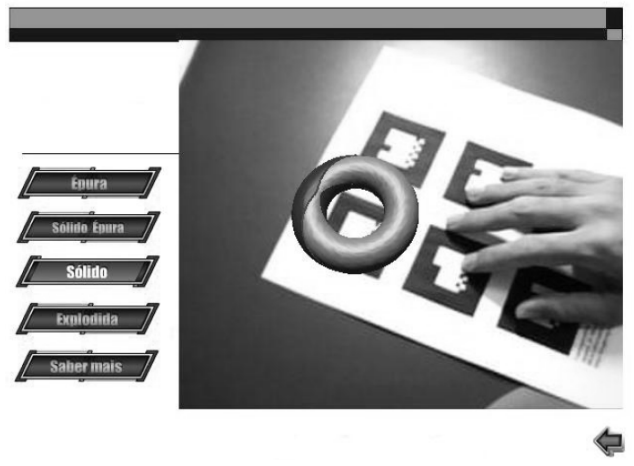

Figura 5 - VGSTARGD desenvolvido pela UFRJ Fonte: Lima et al (2008)

Blum, Sielhorst e Navab (2007) da Universidade Tecnológica de Munique descrevem uma nova técnica para elaboração de feedback automático para AR/VR, onde o foco é ensinar ferramentas de manipulação 3D em Realidade Aumentada em simuladores avançados.

Kaufmann, Steinbüegl, Dünser e Glück (2005) da Universidade Tecnológica de Viena desenvolveram o Construct 3D que é um sistema que usa Realidade Aumentada como um meio para o ensino, e usa 3D para facilitar $o$ ensino da matemática $e$ geometria. A figura 6 mostra os estudantes utilizando o Construct 3D. Essa colaboração educacional serve como base de um estudo 
de avaliação global quanto à eficácia na formação de habilidades espaciais.

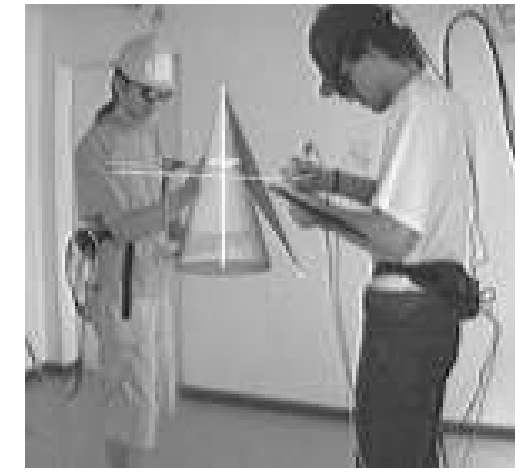

Figura 6 - Estudantes usando o Construct 3D Fonte:

http://www.ims.tuwien.ac.at/media/documents/publicati ons/CT05_GeomEdu_SpatialAbilities.pdf

Souza e Kirner (2011) apresentaram uma aplicação de Realidade Aumentada onde o aluno pode fazer experimentos com um circuito elétrico tal como se estivesse em um mini laboratório e ainda com a opção de ser instruído por um tutor em áudio que explica os efeitos da interação sobre o circuito. A figura 7 mostra este trabalho onde o aluno pode realizar o experimento de Oersted em ambiente de Realidade Aumentada.

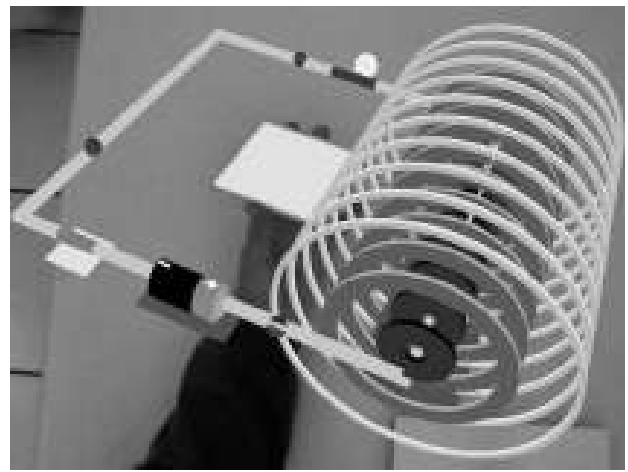

Figura 7 - Experimento de Oersted em Realidade Aumentada

Fonte: Souza e Kirner (2011)

\section{Funcionamento da Realidade Aumentada}

A Realidade Aumentada, a partir de filmar uma cena em tempo real, e a partir de um marcador presente na cena, traz para a tela do computador uma cena em um mundo virtual misturado com um mundo real, que é o mundo em Realidade Aumentada. A formação do ambiente em Realidade Aumentada é exemplificada na figura 8.

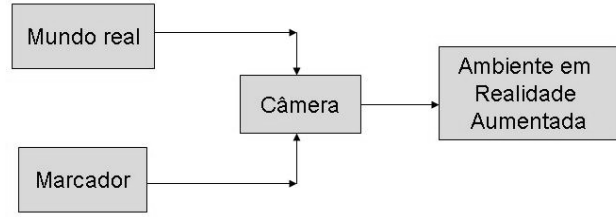

Figura 8 - Formação do mundo em Realidade Aumentada Fonte: Macedo et al (2010)

Para a criação do ambiente em Realidade Aumentada foi utilizado o ARToolKit (Augmented Reality Toolkit), que é uma biblioteca, com código aberto e gratuita, apropriada para desenvolver aplicações de Realidade Aumentada (Zorzal et al, 2008). De acordo com Coelho e Bähr (2005), o ambiente em Realidade Aumentada é formado a partir da mistura da filmagem de um certo local com cenas de um mundo virtual.

A Realidade Aumentada funciona da seguinte maneira:

1-Coloca-se um marcador em um objeto onde se deseja que ocorra a interação;

2-Esse marcador será visualizado pela câmera do microcomputador;

3-Se o mesmo for reconhecido, levará a uma biblioteca pré-estabelecida;

4-Aparecerá, então, na tela do computador, o primeiro objeto onde estava o marcador, juntamente com o objeto que estará na biblioteca.

5-Os dois objetos serão fundidos em um mundo misto que misturará o mundo real com o mundo virtual.

\section{Como Funciona a Realidade Aumentada neste Trabalho}

$\mathrm{Na}$ figura 9 temos um exemplo de Realidade Aumentada onde a usuária e o ímã em forma de barra se encontram no mundo real com um campo magnético do mundo virtual em uma mesma tela. 


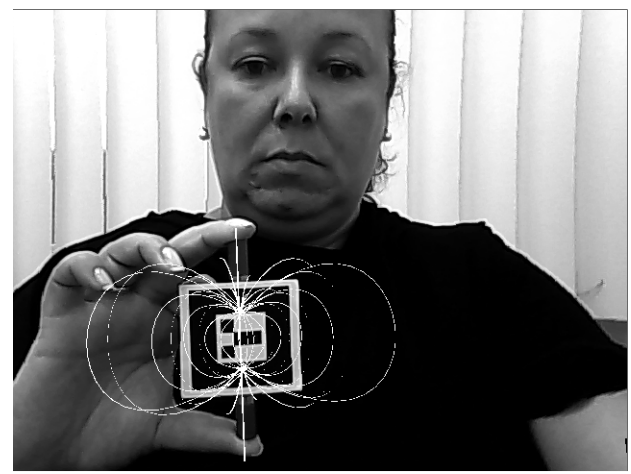

Figura 9 - Usuária com o ímã e seu campo magnético em ambiente de Realidade Aumentada Fonte: autores

O ímã utilizado no experimento pode ser visto na figura 10 .

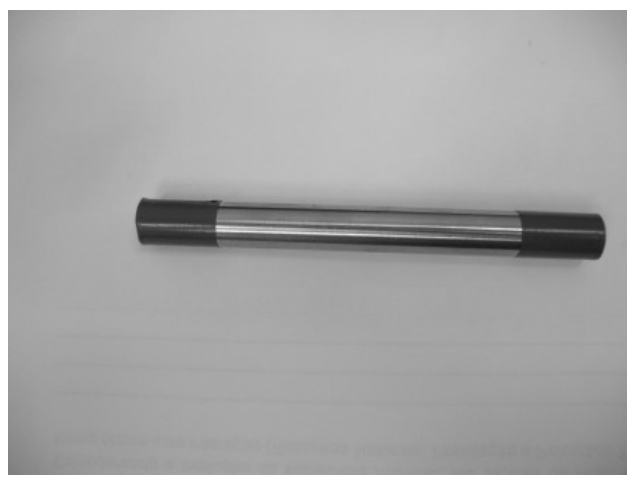

Figura 10 - Ímã utilizado no experimento Fonte: autores

Nesse experimento, o ímã da figura 10 aparecerá em ambiente de Realidade Aumentada juntamente com o seu campo magnético. A partir do momento em que o ímã e o marcador forem mostrados à câmera, a tela do computador trará o mundo em Realidade Aumentada, que, neste caso, será o ímã e seu campo magnético.

Um marcador, como mostrado na figura 11 , é colocado em frente à câmera. Foi estabelecido então o link e surgiu a imagem virtual, que é o campo magnético. Na figura 12 , nota-se que ainda não há a presença do ímã, pois o ímã faz parte do mundo real, e o mesmo, neste momento não está sendo mostrado para a câmera. Nesta figura é demonstrado para que serve o marcador, ou seja, para simplesmente fazer o link e trazer para a tela o mundo virtual. Posteriormente o ímã será mostrado à câmera juntamente com o marcador. Aí então, os dois mundos aparecerão na tela, o real e o virtual, se misturando. Neste caso, o ímã e o seu campo magnético.

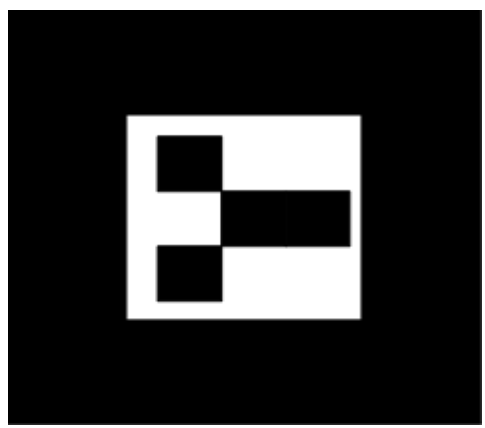

Figura 11 - Marcador utilizado no experimento

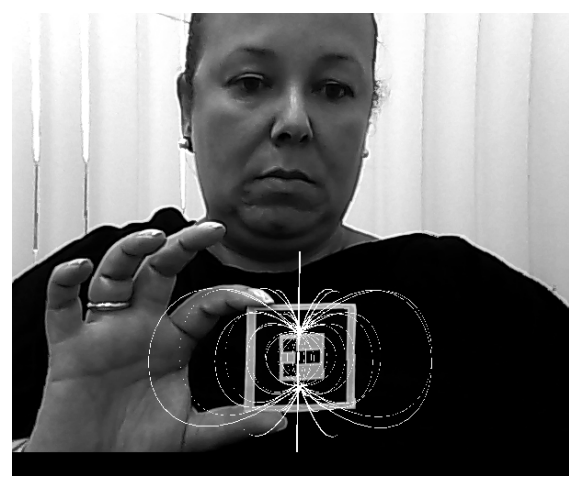

Figura 12 - Marcador sem o ímã sendo colocado em frente à câmera Fonte: autores

O marcador foi colocado logo à frente do ímã e a câmera capturou a imagem. A câmera registrou a imagem do marcador e fez o link com o campo magnético que estava armazenado em uma biblioteca préestabelecida. A usuária, o ímã e o campo magnético encontram-se agora em um ambiente de Realidade Aumentada (figura 13). 


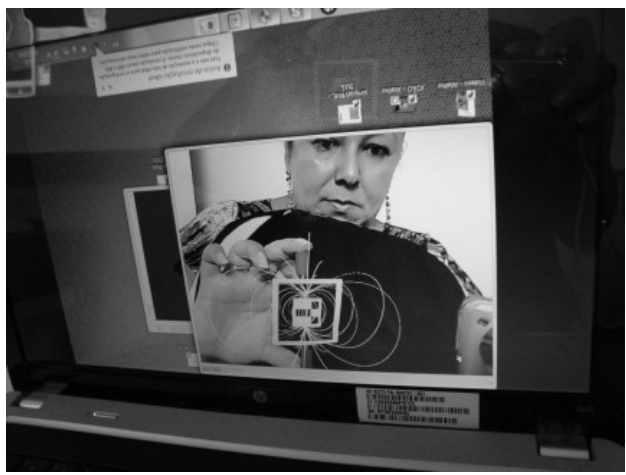

Figura 13 - Usuária, ímã e campo magnético Fonte: autores

A seguir, será demonstrado um exemplo de como se dá a interação com o objeto.

Movimentando-se o marcador no mundo real, ocorre semelhante movimento no objeto que está no mundo virtual. Nota-se esta diferença entre as figuras 14 e 15, onde houve uma mudança na posição do ímã. Primeiramente o ímã está inclinado para o lado esquerdo e, posteriormente, está inclinado para o lado direito, ocorrendo a interação do usuário com o objeto.

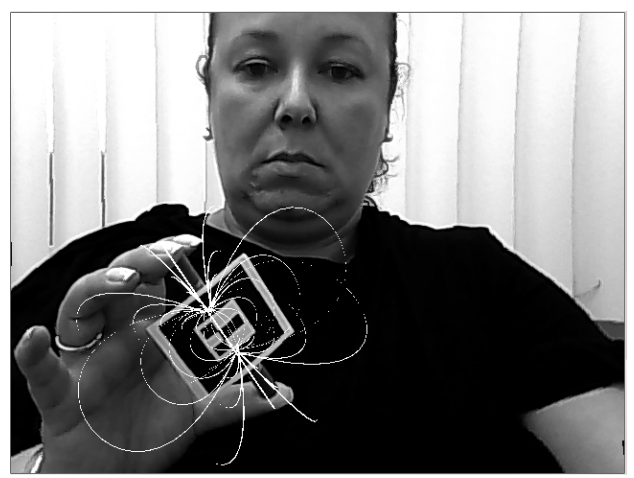

Figura 14 - Ímã inclinado para esquerda Fonte: autores

Posteriormente o ímã foi inclinado para frente, e o seu campo magnético acompanhou o movimento, como pode ser verificado na figura 16 .

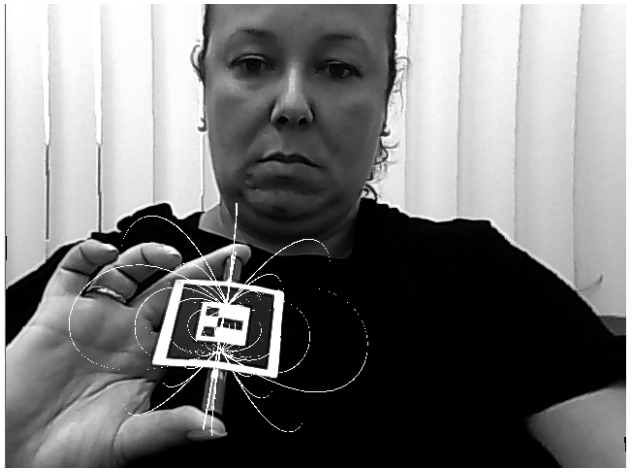

Figura 15 - Ímã inclinado para direita Fonte: autores

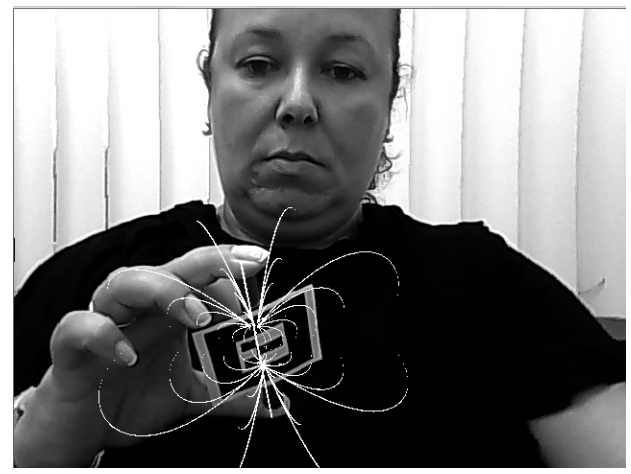

Figura 16 - Ímã inclinado para frente Fonte: autores

Neste experimento, foi feita uma pesquisa com os alunos, onde o campo magnético de um ímã foi misturado ao mundo real em ambiente de Realidade Aumentada.

\section{Experimentos Utilizando Realidade Aumentada com Alunos}

Neste trabalho foram realizados dois experimentos envolvendo os alunos. Estes experimentos foram feitos com o objetivo primeiro de se verificar se 0 aluno conseguiria visualizar o campo magnético de um ímã em forma de barra. Também foram feitas algumas reflexões por parte dos alunos que utilizaram o Objeto de aprendizagem. Foram feitas questões para se verificar se o aluno achou interessante a aula com Realidade Aumentada, se gostaria de ter mais aulas utilizando este ambiente e também foram feitas perguntas em que 
puderam responder livremente. O primeiro experimento foi feito com alunos do curso técnico de Eletrotécnica do Instituto Federal Fluminense campus Itaperuna totalizando 33 estudantes. O segundo experimento foi realizado com estudantes de diversas modalidades de Engenharia. Tais experimentos serão relatados a seguir.

\subsection{Uma Experiência com Estudantes dos Cursos Técnicos de Eletrotécnica}

A intenção deste experimento foi criar um ambiente lúdico em sala de aula, onde o aluno pudesse interagir com o Objeto de Aprendizagem e também pudesse visualizar o mesmo, aumentando também a motivação do aluno com o objetivo de aprender. O aluno pode visualizar o campo magnético de um ímã em forma de barra como nunca experimentado anteriormente. Neste trabalho o aprendiz teve a oportunidade de visualizar o campo magnético em terceira dimensão.

Também o aspecto da motivação foi levado em consideração. Um indivíduo tem necessidades que precisam ser satisfeitas; ao professor cabe fazer com que obtenha satisfação destas necessidades (Mouly, 1963). Com a Realidade Aumentada o aluno teve a oportunidade de visualizar o campo magnético de forma lúdica. Desta forma o processo ensino-aprendizagem será mais atraente $e$, por conseguinte, a aprendizagem será mais eficiente, já que, segundo Mouly (1963), esta eficiência é proporcional à motivação do indivíduo.

O Objeto de Aprendizagem em Realidade Aumentada utilizado pode ser visualizado nas figuras 14,15 e 16 . Neste Objeto podese perceber o campo magnético em volta do ímã em forma de barra que está sendo segurado pela usuária.

Na figura 17 pode-se visualizar um aluno mostrando o marcador que está localizado em cima do ímã em forma de barra para a câmera do lap top em sala de aula. Este marcador fez então o link com o mundo virtual trazendo para a tela o campo magnético.

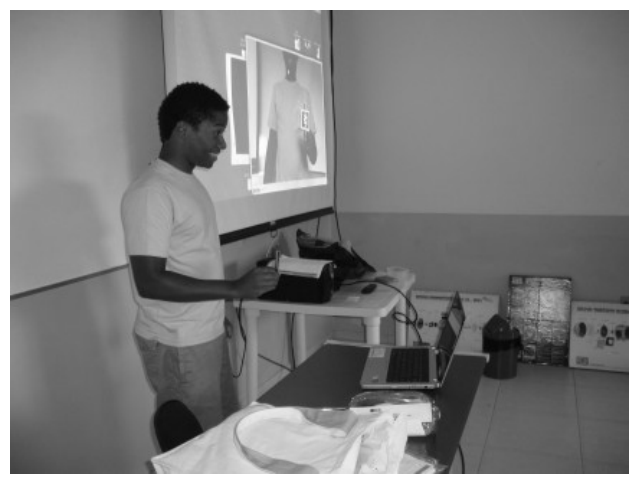

Figura 17 - Aluno mostrando o marcador para a câmera Fonte: autores

No data show da sala de aula é então mostrado o ambiente criado em Realidade Aumentada, como pode ser verificado na figura 18.

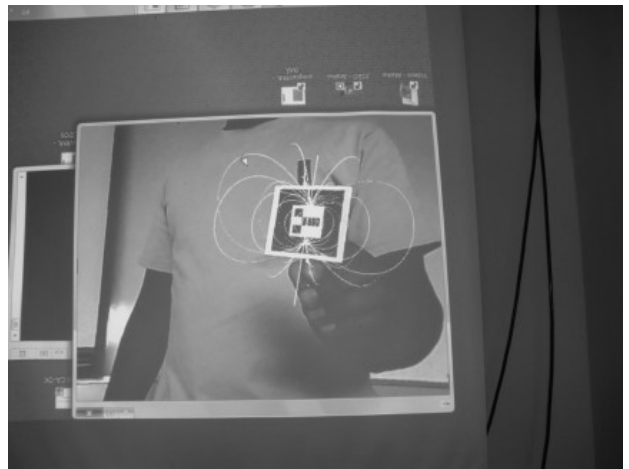

Figura 18 - Ambiente em Realidade Aumentada criado em sala de aula mostrando o campo magnético Fonte: autores

Participaram deste experimento três turmas do curso técnico de Eletrotécnica e uma turma do curso de Eletromecânica do Instituto Federal Fluminense - campus Itaperuna, totalizando 33 alunos, com idades entre 19 e 44 anos. Dos alunos que participaram desse experimento, uma turma de Eletrotécnica é do turno diurno, com um total de 12 alunos e as demais turmas são do turno noturno. Nas figuras 19 e 20 podemos ver os alunos da turma do diurno e uma das turmas do noturno, respondendo o questionário. 


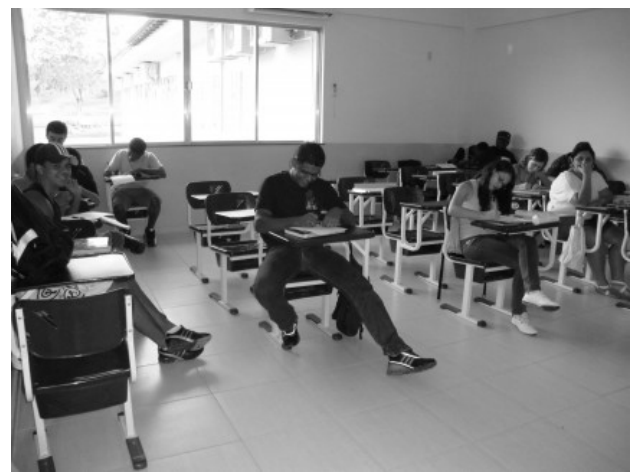

Figura 19 - Turma do diurno respondendo o questionário Fonte: autores

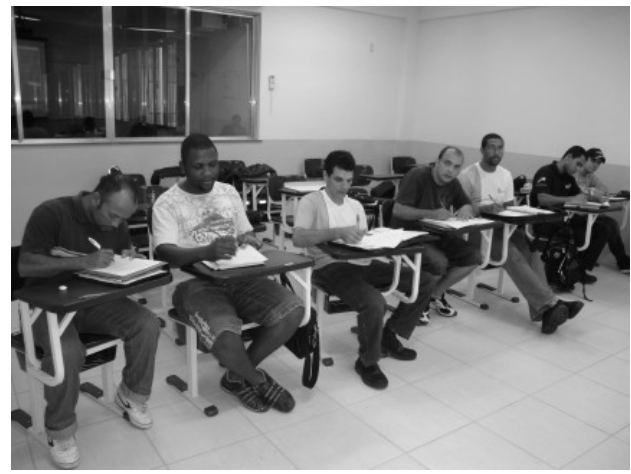

Figura 20 - Ambiente em Realidade Aumentada criado em sala de aula mostrando o campo magnético Fonte: autores

O experimento foi realizado com as turmas nos dias dois e três de março de 2011. Após o experimento os mesmos responderam um questionário e os principais resultados são descritos a seguir.

\subsubsection{Resultados dos Questionários dos Estudantes de Eletrotécnica}

Quando perguntados se acharam fácil usar Realidade Aumentada, 32 alunos responderam que sim e apenas um respondeu que não sabia.

Os 33 alunos responderam, quando questionados, que conseguiram sim, visualizar o campo magnético do ímã em forma de barra.

À pergunta: "Você gostaria de ter mais aulas usando Realidade Aumentada?", também 32 alunos responderam que gostariam e apenas 1 respondeu que não sabe.

Foram feitas também perguntas em que os alunos puderam responder livremente às questões. A seguir serão destacadas as principais respostas:

(A) (20 anos - homem) "Gostei bastante. Achei super útil, funcional e prático para nos ajudar a compreender os fenômenos físicos."

(B) (24 anos - homem) "Achei muito útil e fácil de usar, mas o melhor de tudo e que você vê na prática o que é dito na teoria."

(C) (19 anos - mulher) "Ajudou a entender como funciona na realidade."

(D) (24 anos - homem) "Gostei por causa da visualização de uma coisa que não podemos ver a olho nu."

(E) (21 anos - homem) "Torna mais prático 0 entendimento sobre assuntos difíceis de serem demonstrados."

(F) (29 anos - homem) "Muito interessante, poder observar o campo magnético em 3D."

(G) (44 anos - homem) "Outras matérias poderiam também utilizar esta tecnologia."

(H) (31 anos - homem) "Consegui, até que enfim, ver o campo magnético tão falado."

É importante destacar que não houve nenhuma resposta que demonstrasse resultado negativo por parte dos alunos.

\subsection{Uma Experiência com Alunos dos Cursos de Engenharia}

Neste experimento participaram cinco alunos de engenharia, sendo dois alunos de engenharia mecânica, um aluno de 
engenharia de petróleo, um aluno de engenharia civil e uma aluna de engenharia de produção. Estes alunos têm entre $21 \mathrm{e}$ 27 anos, estão entre o $2^{\circ}$ e $10^{\circ}$ período, no turno noturno e estudam nas seguintes faculdades/universidades: Faculdade Redentor e UNIG, ambas na cidade de Itaperuna/RJ e ISECENSA na cidade de Campos dos Goytacazes/RJ. O experimento foi realizado nos dias 30 de junho e 1 de julho de 2011.

Cada estudante foi levado separadamente a uma sala para que pudesse ser realizado o experimento.

A seguir são descritas as características de cada aluno:

Aluno A: cursa o $10^{\circ}$ período de Engenharia Mecânica na Faculdade Redentor no turno noturno, tem 26 anos e é do sexo masculino;

Aluno B: cursa o $5^{\circ}$ período de Engenharia Mecânica na Faculdade Redentor no turno noturno, tem 22 anos e é do sexo masculino;

Aluno C: cursa o 90 período de Engenharia de Produção no ISECENSA no turno noturno, tem 27 anos e é do sexo feminino;

Aluno D: cursa o 70 período de Engenharia Civil na Faculdade Redentor no turno noturno, tem 25 anos e é do sexo masculino;

Aluno E: cursa o $2^{\circ}$ período de Engenharia de Petróleo na UNIG no turno noturno, tem 21 anos e é do sexo masculino.

Ao final do experimento os alunos responderam um questionário. Os principais resultados são descritos a seguir.

\subsubsection{Resultados dos Questionários dos Estudantes de Engenharia}

Quando perguntados se acharam fácil usar Realidade Aumentada, os cinco alunos responderam que sim.

Os cinco alunos responderam que conseguiram visualizar o campo magnético do ímã em forma de barra e que gostariam de ter aulas utilizando Realidade Aumentada.
Nas perguntas em que puderam responder livremente foram destacadas as respostas mais relevantes:

(Aluno A) "Os fenômenos físicos são de difícil compreensão porque são praticamente invisíveis. A experiência motiva o aluno a estudar física e conhecer as suas origens e conseqüências."..."Achei interessante pois se torna possível visualizar os efeitos magnéticos."

(Aluno B) "A figura impressa deve ter maior associação com o objeto virtual."..."Há benefícios, já que a imagem criada possibilita demonstrar os efeitos em 3 dimensões da linha de campo, diferente do experimento que utiliza limalhas de ferro (2D). O conceito do campo magnético é de difícil entendimento, pelo fato de ser invisível. O programa colaborou no entendimento do assunto."..."Foi interessante porque as linhas de campo mudam com a alteração da posição do objeto."..."Sugiro elaborar figuras mais associativas, tornando os objetos mais didáticos."

(Aluno C) "Achei muito útil. Com poucos recursos foi possível ver em 3D o campo magnético do ímã."..."Me ajudou a revisar o conteúdo agregando conhecimento."... "Sugiro que na programação as linhas magnéticas sejam mais grossas para melhorar a visualização."

(Aluno D) "Útil, ajuda a visualizar."..."Achei que a imagem não estabiliza com muita facilidade."..."Ajuda, pois a visualização 3D é representada com clareza."

(Aluno E) "Muito útil, mostra perfeitamente o campo magnético"..."As linhas e curvas foram expostas com perfeição."

\section{Conclusões e Considerações Finais}

O Objeto de Aprendizagem em Realidade Aumentada proposto visou apresentar aos alunos uma forma de interação e visualização em três dimensões do campo 
magnético de um ímã em forma de barra. Neste trabalho, deseja-se propor uma nova forma de ensinar campos magnéticos. Com este experimento, e de acordo com o questionário respondido pelos alunos, pode se verificar que os alunos conseguiram visualizar o campo magnético de um ímã em forma de barra, além de terem achado fácil utilizar o Objeto de Aprendizagem elaborado em ambiente de Realidade Aumentada. Também, todos gostariam de ter mais aulas utilizando Realidade Aumentada. Segundo as perguntas em que puderam responder livremente, comentaram que acharam útil, prático de usar e que ajuda a compreender os fenômenos físicos. Pelo que foi demonstrado, os alunos conseguiram realmente ver o campo magnético de um ímã em forma de barra de forma em três dimensões e também puderam interagir com este campo.

A Realidade Aumentada apresenta as seguintes vantagens, entre outras:

- Permitiu aos alunos a visualização do campo magnético de um ímã em forma de barra;

- Permitiu a interação do aluno com este campo magnético;
- A partir do momento em que o Objeto de Aprendizagem em Realidade Aumentada foi elaborado, sua utilização é simples e prática;

- Simplicidade e economia do equipamento utilizado: o experimento foi realizado com apenas uma webcam e um laptop.

- Foi utilizado também um data show com telão. Este data show não é necessário, porém, quando se trata de uma turma grande deverá ser utilizado apenas para enriquecer o experimento.

- O ambiente em Realidade Aumentada é excelente para visualização dos campos magnéticos.

Conclui-se, portanto, que, com este aparato tecnológico, as contribuições para a educação serão de grande valia.

\section{Referências}

ARToolKit versão 2.71. DOI= HTTP://www.hitl.washington.edu/research/shared_space/download

BARROS, N. M. Aprendizagem a Distância. Do Rádio Ilustrado à Realidade Virtual Aumentada. Florianópolis, SC: Insular, 2007.

BLUM, T.; SIELHORST, T.; NAVAB, N. Advanced Augmented Reality Feedback For Teaching 3d Tool Manipulation, New Technology Frontiers in Minimally Invasive Therapies, 2007, pp. 223-236, 2007.

BRASIL. Minsitério da Educação. Secretaria de Educação Média e Tecnológica. Parâmetros curriculares Nacionais: ensino médio: Linguagens, códigos e suas tecnologias. Brasília: MEC/SEMTEC, 1999.

BUCHAU, ANDRÉ; RUCKER, WOLFGANG M.; WÖSSNER, UWE; BECKER, MARTIN. Augmented Reality in Teaching Eletrodynamics. The International Journal for Computation and Mathematics in Electrical and Electronic Engineering. Vol. 28 No. 4. 2009. pp 948-963.

COELHO, A. H.; BÄHR, H. P. Visualização de Dados CAD e LIDAR por Meio de Realidade Aumentada. In: XII Simpósio de Sensoriamento Remoto, 16-21 de abril de 2005, INPE, PP. 2925-2932. DOI= http://marte.dpi.inpe.br/col//tid.inpe.br/sbsr/2004/11.11.08.15/doc/2925.pdf

COLL, C. Aprendizagem escolar e construção do conhecimento. Porto Alegre: Artmed, 2000.

COSTA, J. W. Informática na Educação - Uma Síntese. Campinas, SP: Papirus, 1998.

COSTA, J. W.; PAIM, I. Informação e conhecimento no Processo Educativo. In: Costa, J. W.; Oliveira, M. A. M. O. Novas Linguagens e Novas Tecnologias. Petrópolis, RJ: Vozes, 2004. 
GUILLERMO, O. E. P.; TAROUCO, L. M. R.; ENDERES, L. A. M. Desenvolvimento de Objetos Educacionais: Experimentos em Hidráulica. RENOTE - Revista Novas Tecnologias na Educação. Porto alegre, v. 3 №2, novembro, 2005.

KAUFMANN, H; STEINBÜEGL, K; DÜNSER, A; GLÜCK, J. 2005. Feneral Training of Spatial Abilities by Geometry Education in Augmented Reality. In Annual Review of CyberTherapy and Telemedicine: A Decade of $V R$, vol 3, pp. 65-76. DOI= http://www.ims.tuwien.ac.at/media/documents/publications/CT05_GeomEdu_SpatialAbilities.pdf

KENSKI, V. M. Tecnologias e Ensino Presencial e a Distância. Campinas, SP: Papirus, 2003.

LEMOS, B. M., CARVALHO, C. V., Uso da Realidade Aumentada para Apoio ao Entendimento da Relação de Euler. RENOTE. In Revista Novas Tecnologias na Educação. V. 8, p. 1-10, 2010.

LIMA, A. J. R.; CUNHA, G. G.; HAGUENAUER, C. J.; LIMA R. G. R. Torus Surfaces of Descriptive Geometry in Augmented Reality. In $5^{\circ}$ Workshop de Realidade Virtual e Aumentada, 2008, UNESP.

MACEDO, S. H.; LIMA, J. V.; AZEVEDO, F. C. Uso da Realidade Aumentada no Ensino de Sólidos. Congresso Iberoamericano de Informática na Educação. Santiago: Universidad de Chile, p. 179-183, 2010.

MILGRAM, P; KISHINO, F. A Taxonomy of Mixed Reality Visual Displays. 1994. Disponível em: <http://etclab.mie.utoronto.ca/people/paul_dir/IEICE94/ieice.html>. Acesso em: 24/07/2010

MORAN, J. M. Ensino e aprendizagem inovadores com tecnologias audiovisuais e telemáticas. In: MORAN, José Manuel; MASETTO; Marcos T.; BEHRENS, Marilda Aparecida. Novas tecnologias e mediação pedagógica. Campinas, SP: Papirus, 2000. p. 11-66.

MOULY, J. 1963. Psicologia Educacional, 1 ed. São Paulo. Livraria Pioneira Editora.

PAZ, A. M. Atividades Experimentais e Informatizadas: contribuições para o Ensino de Eletromagnetismo. Universidade Federal de Santa Catarina, Florianópolis, 2007. 228 p. Tese de doutorado.

TAJRA, S. F. Informática na educação: novas ferramentas pedagógicas para o professor na atualidade. São Paulo: Érica, 2001.

VALENTE, J. A. eferentes Usos do Computador na Educação. Em Aberto, n. 57 (Jan/Mar/1993), pp. 3-16, 1993.

SOUZA, R. C.; KIRNER, C. Ensino e aprendizagem de eletromagnetismo usando Recursos de Realidade Aumentada. RENOTE - Revista Novas Tecnologias na Educação. Porto alegre, v. 9 №1, julho, 2011.

Recebido em maio de 2011

Aprovado para publicação em junho de 2011

\section{Suzana da Hora Macedo}

Instituto Federal Fluminense - IFF, Brasil.Programa de Pós-Graduação em Informática da Educação e Programa de Pós-Graduação em Ciência da Computação - Universidade Federal do Rio Grande do Sul UFRGS, Porto Alegre - Brasil. E-mail: shmacedo@iff.edu.br

Maria Cristina Villanova Biazus

Programa de Pós-Graduação em Informática da Educação e Programa de Pós-Graduação em Ciência da Computação - Universidade Federal do Rio Grande do Sul - UFRGS, Porto Alegre - Brasil. E-mail: cbiazus@ufrgs.br

\section{Filipe Arantes Fernandes}

Centro Universitário São José de Itaperuna - FSJ, Itaperuna - Brasil. E-mail: filipearantes@fsj.edu.br 